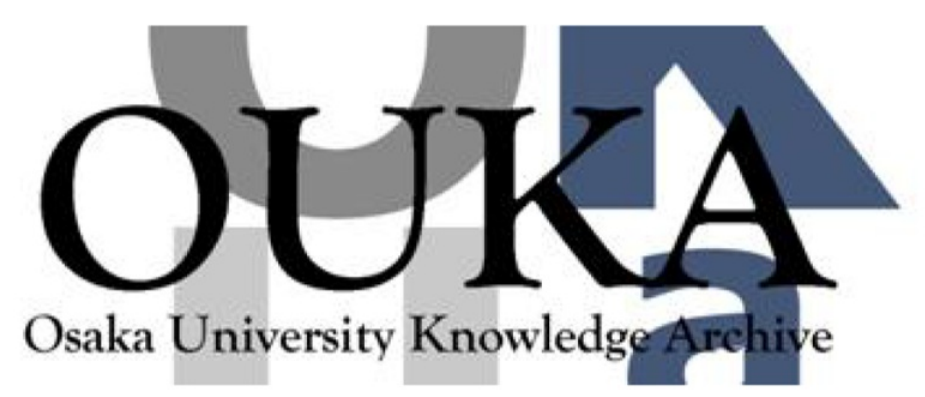

\begin{tabular}{|c|l|}
\hline Title & $\begin{array}{l}\text { Photoinduced luminescence quenching and } \\
\text { insolubilization of star-like branched } \\
\text { organosilicon compounds }\end{array}$ \\
\hline Author(s) & $\begin{array}{l}\text { Sonoda, Tooru; Hidayat, Rahmat; Ozaki, Masanori } \\
\text { et al. }\end{array}$ \\
\hline Citation & Applied Physics Letters. 75(15) p. 2193-p. 2195 \\
\hline Issue Date & $1999-10-05$ \\
\hline oaire:version & VoR \\
\hline URL & https://hdl. handle. net/11094/75837 \\
\hline rights & \\
\hline Note & \\
\hline
\end{tabular}

Osaka University Knowledge Archive : OUKA

https://ir. Library. osaka-u. ac. jp/

Osaka University 


\section{Photoinduced luminescence quenching and insolubilization of star-like branched organosilicon compounds}

Cite as: Appl. Phys. Lett. 75, 2193 (1999); https://doi.org/10.1063/1.124961

Submitted: 12 April 1999 . Accepted: 10 August 1999. Published Online: 05 October 1999

Tooru Sonoda, Hidayat Rahmat, Masanori Ozaki, Katsumi Yoshino, Wolfgang Schneider, Kyung Koo Lee, Akinobu Naka, and Mitsuo Ishikawa

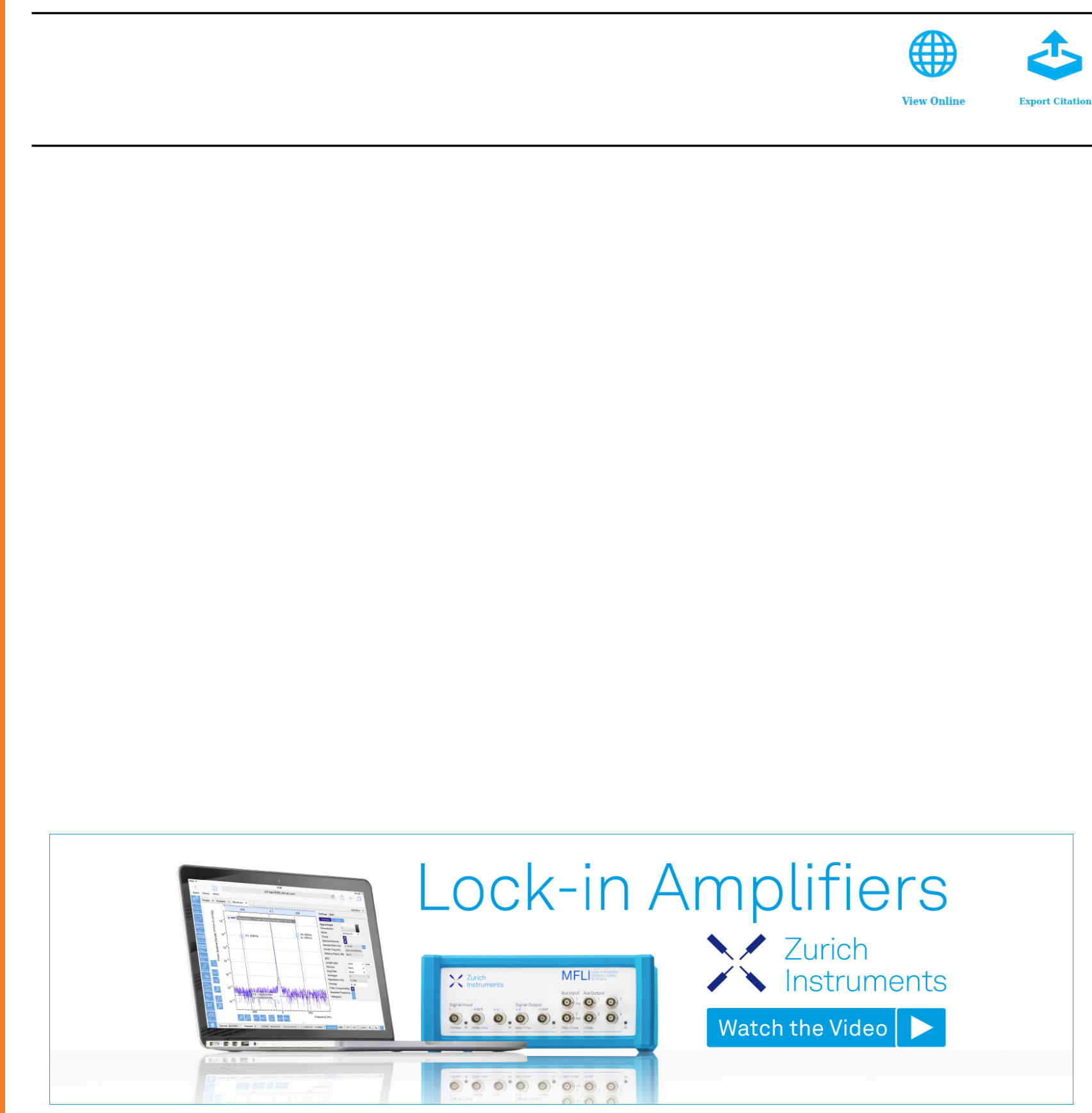




\title{
Photoinduced luminescence quenching and insolubilization of star-like branched organosilicon compounds
}

\author{
Tooru Sonoda, Hidayat Rahmat, Masanori Ozaki, and Katsumi Yoshino ${ }^{\mathrm{a}, \mathrm{b})}$ \\ Department of Electronic Engineering, Graduate School of Engineering, Osaka University, \\ Yamada-oka 2-1, Suita, Osaka 565-0871, Japan \\ Wolfgang Schneider, ${ }^{\text {b) }}$ Kyung Koo Lee, Akinobu Naka, and Mitsuo Ishikawa \\ Department of Chemical Technology, Kurashiki University of Science and the Arts, 2640, Nishinoura, \\ Tsurajima-cho, Kurashiki, Okayama 712-8505, Japan
}

(Received 12 April 1999; accepted for publication 10 August 1999)

\begin{abstract}
Soluble star-like branched organosilicon compounds having silanylene and oligothienylene in their arms are stable in vacuum upon light irradiation, and remain highly light emissive, but degrade upon light irradiation in air. Though the change of absorption spectrum upon light irradiation is not so large, photoluminescence (PL) intensity is strongly suppressed without notable change in spectrum shape. Remarkable shortening of PL decay time due to degradation upon light irradiation in air has been confirmed by time-resolved PL measurement. These results are discussed in terms of scission of $\mathrm{Si}-\mathrm{Si}$ bonds and oxidation. Optical recording utilizing photoinduced insolubilization of these materials has also been demonstrated. (c) 1999 American Institute of Physics.
\end{abstract}

[S0003-6951(99)00441-6]

Conducting polymers with conjugated $\pi$-electron systems in the main chain have attracted much attention from both fundamental and practical interest, because they exhibit some novel properties depending on their molecular structures and various functional applications have been proposed. ${ }^{1-4}$ These properties and device characteristics are strongly dependent on the molecular structures of conducting polymers. It should also be mentioned that some oligomers exhibit similar novel properties and functionality as conducting polymers. Therefore various new conducting polymers and oligomers of unique structures have been synthesized. Recently star-like shaped molecules have also attracted great interest for applications in electroluminescence (EL) devices, because they probably exhibit stable amorphous state, which is an important factor for the operation of devices based on organic materials. ${ }^{5}$

On the other hand, polysilanes with Si backbone have attracted much attention, because they exhibit interesting properties and various functional devices have been demonstrated. ${ }^{6-8}$ However, they are known to be generally not so stable. In this respect, our reports of stable characteristics of oligosilanylene-oligophenylene $e^{9,10}$ and oligosilanylene-oligothienylene ${ }^{11}$ polymers might be quite interesting, because aromatic moieties in the main chain enhance the stability of the silanylene based materials. That is, new composite polymers prepared by combining conjugated oligomer and silanylene oligomers on main chains exhibit unique characteristics reflecting properties of both oligomers. For example, we have recently reported that poly(disilanylene-oligothienylene)s (PDSiOT), in which their backbone main chain structures consist of disilanylene and oligothienylene units, showed intense EL and higher sta-

${ }^{a}$ Electronic mail: yoshino@ele.eng.osaka-u.ac.jp

${ }^{b)}$ Also with: Institute for Fundamental Chemistry, Takao-nishihiraki-cho, Sakyo-ku, Kyoto 606-8103, Japan. bility of their characteristics than simple polysilanylenes. ${ }^{11}$

In this letter, we report the properties of star-like organosilicon molecules and their degradation upon light irradiation in air. Applications of these materials, and these degradation phenomena are also discussed.

Figure 1 shows molecular structures of starlike branched organosilicon compounds used in this experiment. $\mathrm{SiMe}\left(\mathrm{SiMe}_{2} \mathrm{TTBr}\right)_{3}$ has bithienylene (TT) units in the arms, and $\mathrm{SiMe}\left(\mathrm{SiMe}_{2} \mathrm{TTTEt}\right)_{3}$ and $\left.\mathrm{SiMe}\left[\mathrm{SiMe}_{2} \mathrm{TTTSi}_{(\mathrm{iPr}}\right) \mathrm{Si}_{(\mathrm{iPr}}\right) \mathrm{TTTEt}_{3}$ have terthienylene
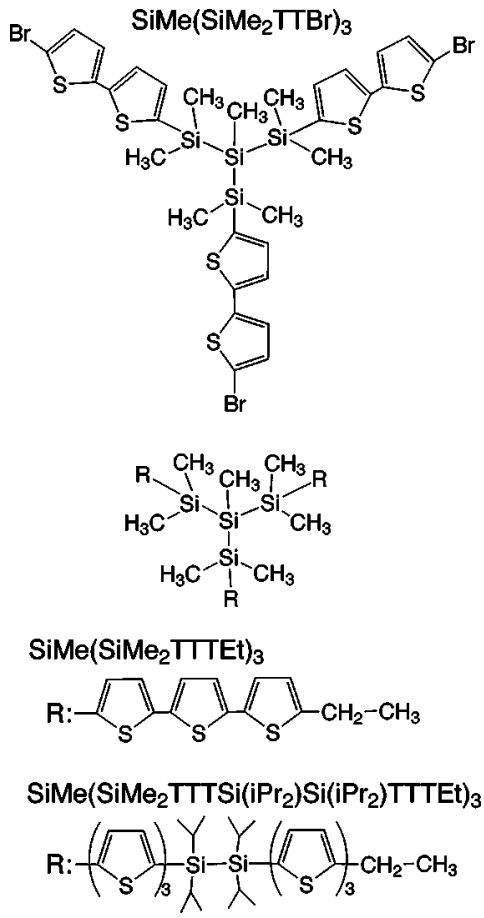

FIG. 1. Molecular structures of star-like branched organosilicon compounds. 


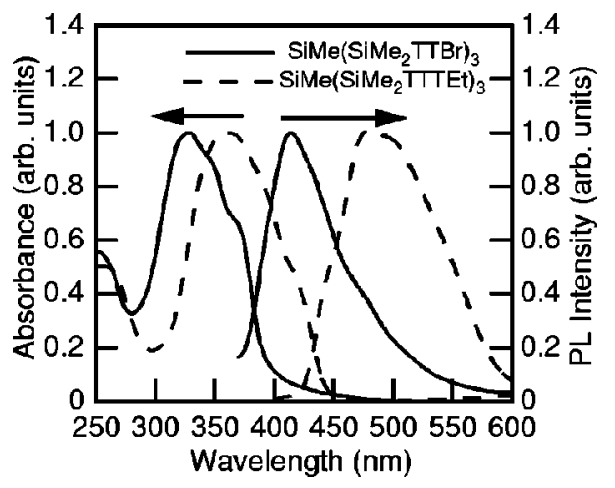

FIG. 2. Absorption and PL spectra of $\mathrm{SiMe}\left(\mathrm{SiMe}_{2} \mathrm{TTBr}\right)_{3}$ and $\mathrm{SiMe}\left(\mathrm{SiMe}_{2} \text { TTTEt }\right)_{3}$.

(TTT) units in the arms, respectively. These star-like branched organosilicon compounds were prepared by the nucleophilic substitution reaction of lithio-oligothiophenyl derivatives with tris(chlorodimethylsilyl)-methylsilane. Detailed preparation method and processing of the branched organosilicon compounds, and their chemical and structural analysis were previously reported. ${ }^{12}$

Thin films of these molecules were formed on quartz substrates by a spin-coating method from chloroform solution. Absorption and PL spectra were measured by a diode array spectrophotometer (8452A, Hewlett Packard) and a fluorescence spectrophotometer (F-2000, Hitachi), respectively.

Time-resolved PL spectrum measurements have been performed utilizing a Ti:sapphire mode-locked laser (Tsumami, Spectra Physics) and a streak scope camera (C4334, Hamamatsu) with a resolution of about 10 ps.

Fourier transform infrared (FTIR) spectroscopy was performed by a spectrometer (FT/IR 300E, Jasco), using a thin film on a $\mathrm{NaCl}$ substrate.

A metal halide lamp $(160 \mathrm{~W})$ was used as a light source for the study of degradation by light irradiation on a sample. Light irradiation in vacuum was performed by utilizing a quartz cell into which a sample was inserted and then evacuated. All measurements were carried out at room temperature.

Figure 2 shows optical absorption and PL spectra of $\mathrm{SiMe}\left(\mathrm{SiMe}_{2} \mathrm{TTBr}\right)_{3}$ and $\mathrm{SiMe}\left(\mathrm{SiMe}_{2} \mathrm{TTTEt}\right)_{3}$ in films. As evident in this figure, the absorption edge and the PL peak of $\mathrm{SiMe}\left(\mathrm{SiMe}_{2} \mathrm{TTTEt}_{3}\right.$ are redshifted compared with those of $\mathrm{SiMe}\left(\mathrm{SiMe}_{2} \mathrm{TTBr}\right)_{3}$, quite similarly to the difference between bithienylene (TT) and terthienylene (TTT). The absorption edge and the PL peak of $\left.\mathrm{SiMe}\left[\mathrm{SiMe}_{2} \mathrm{TTTSi}_{(\mathrm{iPr}}\right) \mathrm{Si}_{(\mathrm{PPr}}\right) \mathrm{TTTEt}_{3}$ were similar to those of $\mathrm{SiMe}\left(\mathrm{SiMe}_{2} \mathrm{TTTEt}\right)_{3}$. These facts suggest that optical properties of star-like branched organosilicon compounds are determined by oligothienylene in the arms, which is consistent with linear oligosilanylene molecules and polymers. $^{10,11}$

Figure 3 shows the change of absorption spectrum of $\mathrm{SiMe}\left(\mathrm{SiMe}_{2} \mathrm{TTTEt}\right)_{3}$ upon light irradiation in air and vacuum. The absorption peak at around $360 \mathrm{~nm}$, corresponding to the absorption of terthienylene rings, decreased after light irradiation of $30 \mathrm{~min}$ in air. On the other hand, as shown in Fig. 3(b), the change of the absorption spectrum

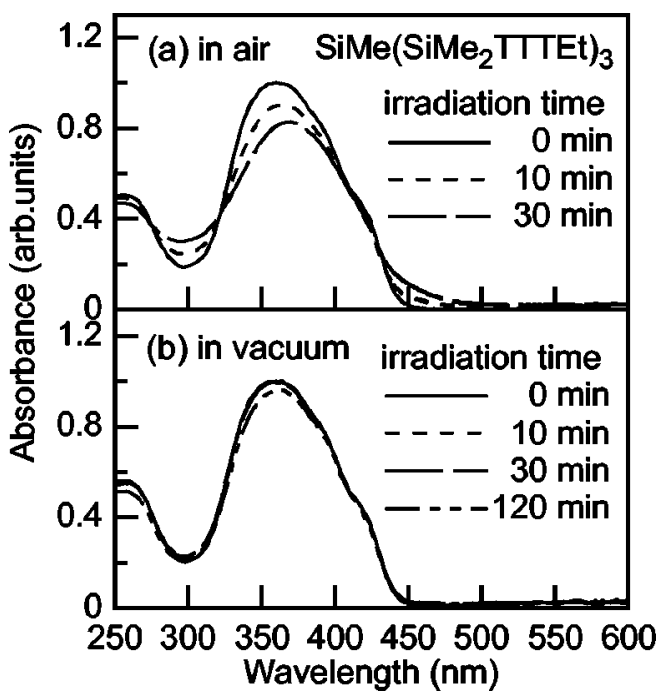

FIG. 3. Change of absorption spectrum of $\mathrm{SiMe}\left(\mathrm{SiMe}_{2} \mathrm{TTTEt}\right)_{3}$ upon light irradiation (a) in air (b) in vacuum.

was negligible even after light irradiation of $120 \mathrm{~min}$ in vacuum.

Figure 4 shows the change of PL spectrum of $\mathrm{SiMe}\left(\mathrm{SiMe}_{2} \mathrm{TTTEt}\right)_{3}$ upon light irradiation in air and vacuum. The PL intensity of $\mathrm{SiMe}\left(\mathrm{SiMe}_{2} \mathrm{TTTEt}\right)_{3}$ decreased dramatically upon light irradiation in air. After light irradiation of $30 \mathrm{~min}$ the PL intensity decreased by about three orders of magnitude. On the other hand the decrease of PL intensity was much lower upon light irradiation in vacuum, as shown in Fig. 4(b).

This fact suggests that oxygen in the air plays an important role in the suppression of PL by light irradiation. The fact that the effect of light irradiation is much more pronounced in PL compared with that in the absorption spectrum, suggests that oxygen should have influenced the excited state, or perhaps the dynamics of optically excited excitons. Negligible change in the absorption spectrum in vacuum even after long-time light irradiation suggests that these organosilicon compounds are stable in vacuum. The small drop of PL intensity after light irradiation in vacuum may be due to the effect of remaining oxygen in the film. These results suggest that this molecule is stable in vacuum upon light irradiation and remains highly emissive. Green intense EL peaked at $520 \mathrm{~nm}$ was also observed in a device utilizing $\mathrm{SiMe}\left(\mathrm{SiMe}_{2} \mathrm{TTTEt}\right)_{3}$ with the structure of $\mathrm{MgIn} /$

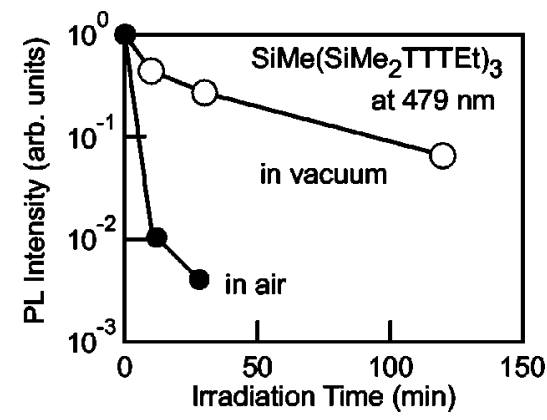

FIG. 4. Change of PL spectrum of $\mathrm{SiMe}\left(\mathrm{SiMe}_{2} \mathrm{TTTEt}_{3}\right.$ upon light irradiation (a) in air (b) in vacuum. Inset: time dependence of PL intensity during light irradiation. 


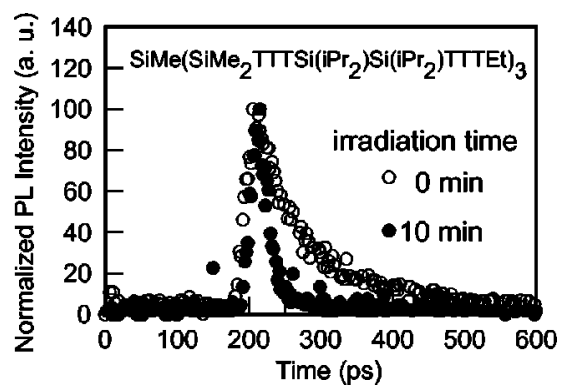

FIG. 5. Decay of PL intensity of pristine $\mathrm{SiMe}\left[\mathrm{SiMe}_{2} \mathrm{TTTSi}\left(\mathrm{iPr}_{2}\right)\right.$ $\mathrm{Si}\left(\mathrm{PPr}_{2}\right) \mathrm{TTTEt}_{3}$ and $\mathrm{SiMe}\left[\mathrm{SiMe}_{2} \mathrm{TTTSi}_{(} \mathrm{Pr}_{2}\right) \operatorname{Si}_{(}\left(\mathrm{Pr}_{2}\right)$ TTTEt $]_{3}$ after light irradiation of $10 \mathrm{~min}$.

organosilicon/ITO, which will be reported in detail in another paper.

Time-resolved PL measurement was carried out using a thin film of $\left.\left.\mathrm{SiMe}\left[\mathrm{SiMe}_{2} \mathrm{TTTSi}_{(\mathrm{iPr}}\right) \mathrm{Si}_{(\mathrm{iPr}}\right) \mathrm{TTTEt}\right]_{3}$ to investigate the effect of degradation phenomenon on dynamics of excitons. The stationary PL spectrum had two peaks at 479 and $525 \mathrm{~nm}$. The PL at $479 \mathrm{~nm}$ is interpreted to be originated from radiative decay of excitons in this compound. The decay time of this peak is about $70 \mathrm{ps}$ in vacuum as shown in Fig. 5. After light irradiation of $10 \mathrm{~min}$ in air, the film was again inserted into a vacuum chamber for timeresolved PL measurement. As shown in Fig. 5, the PL intensity was suppressed. In addition, the PL decay time was remarkably shortened. This result indicates that quenching sites were formed by the light irradiation in air, possibly because of photoreaction of the molecules with oxygen. An exciton produced in thienylene units in the arm of this organosilicon compound must be quickly dissociated upon collision with a quenching center before radiative recombination, resulting in the shortening of PL decay time and the decrease in the emission intensity.

In FTIR spectra of $\mathrm{SiMe}\left(\mathrm{SiMe}_{2} \mathrm{TTTEt}\right)_{3}$ the absorption peak at around $1070 \mathrm{~cm}^{-1}$ was confirmed to increase significantly with increasing irradiation time in air. This peak corresponds to a vibration of $\mathrm{Si}-\mathrm{O}-\mathrm{Si}$ or $\mathrm{Si}-\mathrm{O}-\mathrm{C}$ unit. Therefore it should be noted that the oxidation of $\mathrm{Si}$ appeared to occur upon light irradiation in air.

Furthermore, photoinduced insolubilization of the films of these materials was observed. That is, upon irradiation of UV light in air these organosilicon compounds become nonsoluble or poor soluble in organic common solvents. It should be mentioned that these star-like organosilicon compounds containing silanylene are more soluble than the corresponding silanylene oligomer itself and also upon UV light irradiation scission of $\mathrm{Si}-\mathrm{Si}$ bonds may occur, resulting in the formation of the film of thienylene derivative. In the beginning we are speculating the formation of thienylene derivative films of low solubility upon light irradiation. However, FTIR measurements also suggest the possibility of cross linkings. Consequently, the insolubilization of the films of these materials may be due to both the formation of short thienylene derivatives and the cross linkings according to the oxidation of Si.

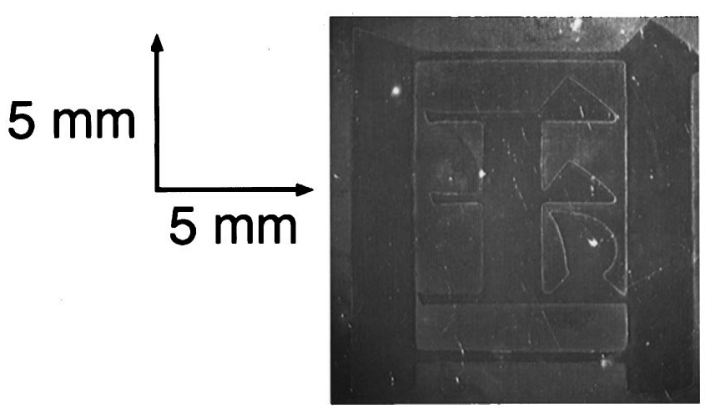

FIG. 6. An optical recorded pattern produced by UV light irradiation followed by washing with chloroform.

It should also be mentioned that the insoluble film which was obtained by light irradiation and can be interpreted, in other words, as the photodegraded one still keeps the original color.

Therefore, these phenomena can be used for optical recording. A spin-coated film of $\mathrm{SiMe}\left(\mathrm{SiMe}_{2} \mathrm{TTTEt}\right)_{3}$ on a glass substrate was light irradiated in air through a mask. Then the irradiated area became insoluble and nonirradiated area was removed by immersing in chloroform. Figure 6 shows an example of optical recording of a Kanji character. It should also be mentioned that patterned EL can be realized in an EL device prepared by preirradiating the organosilicon compound film in the device with UV light. Because the EL is completely suppressed in the preirradiated area, the pattern of EL precisely coincides with the pattern of nonirradiated area.

This work was supported by the Research for the Future Program from the Japan Society of the Promotion of Science (JSPS-RFTF96P00206).

${ }^{1}$ K. Yoshino, K. Kaneto, and Y. Inuishi, Jpn. J. Appl. Phys., Part 2 22, L567 (1983).

${ }^{2}$ J. H. Burroughes, D. D. C. Bradley, A. R. Brown, R. N. Marks, K. Mackay, R. H. Friend, P. L. Burns, and A. B. Holmes, Nature (London) 347, 539 (1990).

${ }^{3}$ Y. Ohmori, M. Uchida, K. Muro, and K. Yoshino, Jpn. J. Appl. Phys., Part 2 30, L1941 (1991).

${ }^{4}$ S. Morita, A. A. Zakhidov, and K. Yoshino, Solid State Commun. 82, 249 (1992).

${ }^{5}$ M. Thelakkat and H.-W Schmidt, Adv. Mater. 10, 219 (1998).

${ }^{6}$ R. West, L. D. David, P. I. Djurovich, K. L. Stearly, K. S. V. Srinivasan, and H. Yu, J. Am. Chem. Soc. 103, 7352 (1981).

${ }^{7}$ K. Yoshino, K. Yoshimoto, M. Hamaguchi, T. Kawai, A. A. Zakhidov, H. Ueno, M. Kakimoto, and H. Kojima, Jpn. J. Appl. Phys., Part 2 34, L141 (1995).

${ }^{8}$ A. Fujii, K. Yoshimoto, M. Yoshida, Y. Ohmori, K. Yoshino, H. Ueno, M. Kakimoto, and H. Kojima, Jpn. J. Appl. Phys., Part 1 35, 3914 (1996).

${ }^{9}$ K. Hosoda, K. Tada, M. Ishikawa, and K. Yoshino, Jpn. J. Appl. Phys., Part 2 36, L372 (1997).

${ }^{10}$ K. Yoshino, K. Tada, M. Hirohata, R. Hidayat, S. Tatsuhara, M. Ozaki, A. Naka, and M. Ishikawa, Jpn. J. Appl. Phys., Part 2 36, L1548 (1997).

${ }^{11}$ K. Yoshino, A. Fujii, H. Nakayama, S. Lee, A. Naka, and M. Ishikawa, J. Appl. Phys. 85, 414 (1999).

${ }^{12}$ K. K. Lee, A. Naka, and M. Ishikawa, Proceedings of the Third Symposium on Atomic-Scale Surface and Interface Dynamics (to be published). 